\title{
Evaluating the Safety of Intravenous Delivery of Autologous Activated Platelet-rich Plasma
}

\author{
Karina Karina1,2,3,4,5*, Krista Ekaputri1', Johannes Albert Biben', Ratna Herawati Purwoko', \\ Tommy Partunggul Sibuea', Sarah Listyo Astuti', Anastasia Maria Loho', Yuliardy Limengka', Nelfidayani', \\ Agustini S1, Grady Krisandi²,3, Azza Maryam', Imam Rosadi2,6, lis Rosliana², Siti Sobariah², \\ Wismo Reja Subroto², Irsyah Afini², Tias Widyastuti², Alfida Zakiyah², Difky Ernanda², Noor Aini², Jusryanti', \\ Sulaeha AD ${ }^{1}$, Sristin Indah Prestiani', Indah Mustika Donna', Habibi', Meyla Shinta Mutiara
}

${ }^{1}$ Klinik Hayandra, Yayasan Hayandra Peduli, Jakarta, Indonesia, ${ }^{2}$ Hayandra Lab, Yayasan Hayandra Peduli, Jakarta, Indonesia, ${ }^{3} \mathrm{Faculty}$ of Medicine, University of Indonesia, Jakarta, Indonesia, ${ }^{4}$ Faculty of Medicine, Universitas Pembangunan Nasional Veteran Jakarta, Jakarta, Indonesia, ${ }^{5}$ Pusat Kajian Stem Cell, Universitas Pembangunan Nasional Veteran Jakarta, Jakarta, Indonesia, ${ }^{6}$ Department of Biology, Faculty of Mathematics and Natural Sciences, Mulawarman University, Indonesia

\section{ABSTRACT}

Introduction: Autologous platelet-rich plasma (PRP) has been a growing trend in the field of medicine due to its broad range of application and is considered safe from bloodborne diseases. Furthermore, various studies have tried to optimize the use of autologous PRP through various preparation protocols, including PRP activation. However, most of the studies available have not evaluated the safety for intravenous delivery of PRP, especially autologous activated PRP (aaPRP). Therefore, this study aimed to evaluate the safety of intravenous delivery of aaPRP.

Methods: Blood was drawn from each patient and aaPRP was isolated through calcium activation and light irradiation. Each aaPRP was administered intravenously to all patients. Adverse events were documented and analyzed.

Results: Six hundred eleven patients participated in this study with a total of 4244 aaPRP therapies. Quality control of autologous aaPRP showed no platelets present after both calcium activation and light irradiation. No adverse events such as allergic reaction, infection, and coagulation problems were observed on all patients over the course of the study. Conclusion: Our results showed that intravenous administration of autologous aaPRP is safe even in patients with various pathological conditions.

Keywords: Intravenous infusion, platelet-rich plasma, safety

\section{INTRODUCTION}

Platelet-rich plasma (PRP) is a high platelet concentrate extracted from the processed autologous plasma of the whole blood (1). A total of more than 1100 proteins have been found in PRP with different functions, ranging from enzymes, growth factors, and messengers of the immune system (2). These proteins and many bioactive factors are mainly secreted by three types of granule (alpha, delta, lambda) within the platelets, with alpha granules being the most abundant. Platelet activation is required for the release of these proteins and bioactive factors by alpha granules (3). Secreted proteins and bioactive factors upon activation are found to take part in various biological processes, including

Corresponding author: Karina Karina, Klinik Hayandra, Yayasan Hayandra Peduli, Jakarta, Indonesia, Hayandra Lab, Yayasan Hayandra Peduli, Jakarta, Indonesia, Faculty of Medicine, University of Indonesia, Jakarta, Indonesia, Faculty of Medicine, Universitas Pembangunan Nasional Veteran, Jakarta, Indonesia. E-mail: karina@hayandra.com

Submitted: 04 March 2021/Accepted: 26 April 2021

DOI: https://doi.org/10.17532/jhsci.2021.1276 cellular proliferation and differentiation, matrix remodeling, and angiogenesis. These biological processes are found to enhance wound healing and tissue regeneration (2).

Various protocols of PRP preparation exist with the basic steps consist of: (1) Blood collection, (2) centrifugation, (3) plasma aspiration, (4) potential second centrifugation, (5) selected supernatant removal, (6) mixing/resuspension of platelets, (7) activation, and (8) application (4). Among all of the basic steps, platelet activation is a crucial step in PRP preparation. Through activation, degranulation of alpha granules, which releases growth factors, will be more optimal and leads to higher availability of bioactive molecules (5).

PRP is a growing trend in medical field, with the application ranging from cardiovascular to ocular disease (6). In plastic surgery, the clinical application of PRP to date includes wound healing, fat grafting (7), bone grafting, skin and face rejuvenation, and hair restoration $(4,8)$. With such broad popularity and range of application, the safety of PRP therapy becomes a crucial topic. Since PRP therapy is autologous, it is safer with no concern of bloodborne 
disease transmission (9). Regarding the mode of delivery, the current researches and reports about PRP involve various modes of delivery; the most common ones include topical and local injection (intradermal and subcutaneous) and intraarticular $(10,11,12,13)$. Very few studies performed intravenous injection (14).

Although PRP therapy is considered safe, there were some reported or possible adverse events. There were safety concerns with intravenous delivery since there are limited studies on this subject. Concerns on adverse events for intravenous injection of PRP therapy include allergic reaction, infection, and coagulation problems (15).

To the authors' knowledge, there is no study evaluating the safety of intravenous delivery of PRP with a large sample size. Thus, this study aims to investigate the safety of intravenous autologous activated PRP (aaPRP) for various pathological conditions.

\section{METHODS}

This was a retrospective study involving patients with various pathological conditions that were treated with autologous aaPRP in Hayandra Clinic. Our inclusion criteria were male and female adult patients (aged 19-75 years old). As for exclusion criteria, we excluded patients with thromboembolic conditions. Follow-up of the patients was done every 3-4 months during the course of our study. Ethical clearance was obtained from Health Research Ethics Committee, University of Indonesia, and Cipto Mangunkusumo Hospital (HREC-FMUI/CMH). Data were collected from the patients' medical records with informed consent obtained from each patient enrolled in this study.

\section{Group of pathology}

Patients were classified into 7 pathological groups. Pathological groups consist of diabetes mellitus, hypertension, stroke, osteoarthritis, post-cardiac stenting, anti-aging, and other pathologies. Other pathologies consist of hepatitis, psoriasis, chronic obstructive pulmonary disorder, dementia, and Parkinson.

\section{PRP preparation}

Venous blood with volume of $24 \mathrm{~mL}$ was withdrawn from the patient and divided into 8 sodium citrate blood collection tubes $\left(0.5 \mathrm{~mL}\right.$ each tube) (BD Vacutainer ${ }^{\circledR}$, New Jersey, USA). The blood tubes were centrifuged with $188 \mathrm{G}$ speed for $10 \mathrm{~min}$ (SL16 Centrifuge Series, Thermo Fisher Scientific, Massachusetts, USA). The separated plasma layer was aspirated, collected with transfer pipette, and subjected to second centrifugation of $1690 \mathrm{G}$ for $10 \mathrm{~min}$. Plasma was then removed until the final volume in the tube was $2.5 \mathrm{~mL}$. The pellets of platelets were resuspended in the remaining plasma in the tube $(2.5 \mathrm{~mL})$ which was considered as inactivated PRP. Calcium activator (H-Remedy, Hayandra, Indonesia) $(0.15 \mathrm{~mL})$ was added and mixed with the inactivated PRP until clots were formed. Clots were then eliminated and $10 \mathrm{~mL}$ of $\mathrm{NaCl} 0.9 \%$ was added. The PRP was then subjected to light activation (AdiLight-1, Adistem Ltd., Hong Kong) for $20 \mathrm{~min}$. The aaPRP was administered intravenously with blood transfusion set tube to remove potential cellular debris (Terumo, Shibuya, Japan) to the patient.

\section{Quality control of PRP}

Around $200 \mu \mathrm{L}$ of PRP aliquot was moved into $1.5 \mathrm{~mL}$ sterile microtubes. Analysis of sample was done using Sysmex KX-21 (Sysmex Corporation, Japan) automated hematology analyzer that has been calibrated before analyzing the platelet counts of PRP. Each aaPRP batch was analyzed twice in every processing stage for platelet count measurement.

\section{Data collection and analysis}

A retrospective analysis was performed on aaPRP-treated patients with various pathological conditions from January 2016 to December 2020. Included variables were gender, age, number of PRP treatment, pathological condition, and incidence of adverse reactions. Adverse events include side effects or patient discomforts or complaints, while serious adverse events include life-threatening conditions that require major intervention or hospitalization. Data was further analyzed descriptively, as shown in the figures.

\section{RESULTS}

\section{Patient demographics and PRP administration}

Among 611 patients, 284 (46.48\%) patients were male and $327(53.52 \%)$ patients were female. The median age was 49 years old. The youngest patient was 19 years old and the oldest patient was 75 years old. A total of 4244 aaPRP therapy was done throughout the study.

Diabetes mellitus was the most common pathological condition found in the patients, followed by osteoarthritis, hypertension, stroke, post-cardiac stenting, anti-aging, and other pathological conditions. The distribution percentage of patient's pathological conditions is shown in Figure 1.

\section{Quality control of PRP}

The blood of the patient was analyzed for blood cells and platelets count. The patient's platelets were counted in each stage of PRP preparation and shown in Figure 2. High platelet count of $1328 \times 10^{3} / \mu \mathrm{L}$ was found in PRP but significantly decreased to $5 \times 10^{3} / \mu \mathrm{L}$ post-activation with calcium activator. Further photo-activation of PRP reduced platelet count to nearly zero.

Leukocytes were also counted in each stage of PRP preparation and shown in Figure 3. PRP had leukocyte count of $0.6 \times 10^{3} / \mu \mathrm{L}$ and significantly reduced to zero with calcium activation and photo-activation.

\section{Safety analysis}

Among all patients, no allergic reactions, infections, and coagulation problems were observed. No serious adverse events that caused life-threatening condition that required hospitalization or urgent interventions happened in this study. Overall, no aaPRP-related adverse events were reported among all patients that participated in the study. 


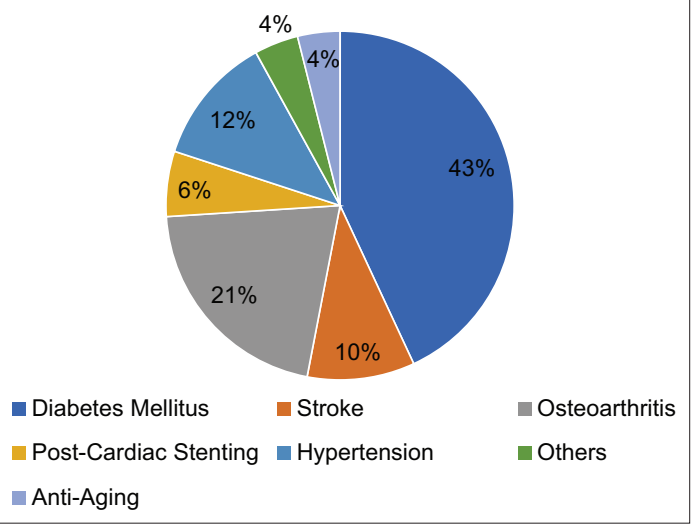

FIGURE 1. Distribution of patient's pathological conditions.

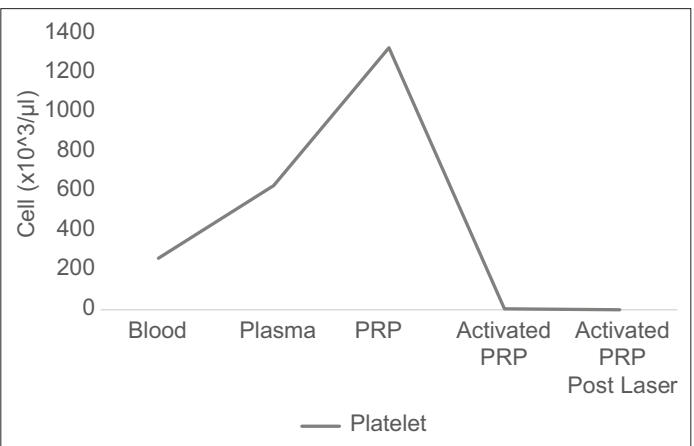

FIGURE 2. Platelet count from venous blood until final autologous activated platelet-rich plasma product.

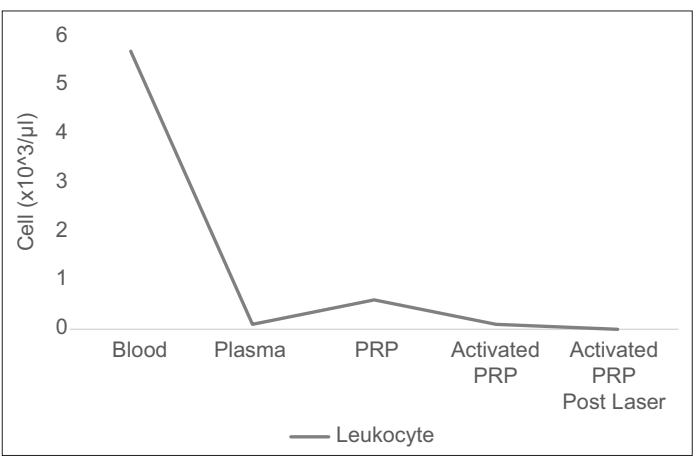

FIGURE 3. Leukocyte count from venous blood until final autologous activated platelet-rich plasma product.

\section{DISCUSSION}

Previous studies have evaluated the safety of PRP for localized administration. However, the safety for intravenous PRP administration has not been evaluated (10). To our knowledge, this study is the first study involving large number of patients to evaluate the safety of intravenous administration of aaPR in various pathological conditions.

Double centrifugation protocol was used in our study. Through sterile centrifugation process, platelets will be separated from red blood cells and sequestrate platelets in high concentration without causing damage or lysis of platelet to avoid triggering premature release of growth factors (16). The optimal or "therapeutic" platelet concentration of PRP should be 4- to 5-fold greater than that of the whole blood (17). According to the animal trial done by Nagata et al., between double-centrifugation and single-centrifugation protocol, the former one yielded higher platelet concentrations, but the setback was it caused alterations in platelet morphology and, therefore, was more sensitive to small processing error. The important point is that in the above trial, therapeutic PRP was produced only by the double centrifugation protocol (16).

In our study, calcium activator-light irradiation-activated PRP was used due to better efficacy and safety. The rationale behind the use of calcium activation was to activate platelets so growth factors would be secreted from the $\alpha$-granules without the need for the patient's body to activate the platelets $(8,18)$. Furthermore, activation leaves no platelets in the activated PRP which prevents potential thromboembolic events (19). It has been shown that photo-activation of PRP with low-level light decreases the concentration of pro-inflammatory cytokines, such as interleukin-2 (IL-2) and IL-6, and increases the concentration of leukocyte-derived anti-inflammatory factors, such as IL-1 receptor antagonist (IL-1RA) and IL-2RA (20,21,22). Two case studies by Freitag et al. showed that the patients treated with activated PRP demonstrated improvement in clinical outcome of osteoarthritic patients $(23,24)$. In contrast, a clinical trial in osteoarthritis cases done by Paterson et al. showed that there were no statistically significant improvements in the activated PRP group when compared to the control (hyaluronic acid) group (11). However, all these studies demonstrated no side effect or complication of activated PRP; hence, it may be considered as a safe treatment option $(11,23,24)$. Furthermore, with increased concentration of anti-inflammatory factors, aaPRP may also act as an anti-aging agent that helps reduce chronic systemic inflammation which is one of the major markers of aging (25). Our study confirmed that the activation step of our processing technique successfully activate the PRP as indicated by the significant decline of the platelet count. Possible reported adverse events of PRP through intravenous administration include allergic reactions, infections, and coagulation problems. Allergic reactions may happen due to the substances used to prepare PRP as reported by Michal et al. (26). Improper processing and administration of PRP may also cause infections (15). The presence of platelets in PRP has also raised concern for causing thrombosis (27). As for this study, no adverse events were reported in all 611 patients.

There were no allergic reactions related to aaPRP administration in our patients as an autologous therapy generally has a low risk of allergic reaction complication. Our study also did not find any infection-related complications due to the administration of aaPRP as Reddy et al. mentioned (15). The preparation of our aaPRP was handled with aseptic and antiseptic technique to maintain its sterility from the time of blood withdrawal until its administration to the patient. No coagulation problems such as thromboembolic events were observed in this study. This can be explained because, during the processing period, all clots had been removed meticulously. In addition to that, the PRP was administered through blood transfusion set tube so that any possible remnant of clots would be filtered out before it entered the circulation. The activation of PRP with calcium activator and light irradiation reduced the number of platelets to nearly 
zero and leukocytes to zero. This implies that when aaPRP was administered to the patient, there were virtually no platelets and leukocytes left that may potentially cause thrombosis (19).

A systematic review and meta-analysis have found that PRP which is rich in wound healing-related growth factors, such as vascular endothelial growth factor and platelet-derived growth factor, helps in patients with diabetic ulcer $(28,29)$. PRP has also been reported to be beneficial for ischemic stroke, osteoarthritis, and chronic ulcers. There have been no previous reports regarding the adverse event of PRP use in those cases or its combination with stromal vascular fraction $(11,12,30,31,32,33)$. Our study showed that the intravenous administration of aaPR in patients with various pathological conditions did not cause any adverse event. Thus, aaPRP for therapy in various pathological conditions is safe for patients and might even be beneficial to treat their pathological condition.

The limitation of this study is the absence of objective evaluation to measure the efficacy of aaPRP as a therapy for various pathological conditions. Although aaPRP is proven to be safe, further prospective study is required to objectively evaluate the efficacy of aaPRP as a therapy for various pathological conditions.

\section{CONCLUSION}

The use of aaPRP intravenously in this study showed no allergic reactions, infections, and coagulation problems despite various patients pre-existing conditions. This suggests that intravenous injection of aaPRP is safe with no adverse effects.

\section{COMPETING INTERESTS}

The authors declare no conflicts of interest.

\section{REFERENCES}

1. Wu PIK, Diaz R, Borg-Stein J. Platelet-rich plasma. Phys Med Rehabil Clin N Am 2016;27(4):825-53.

2. Du R, Lei T. Effects of autologous platelet rich plasma injections on facial skin rejuvenation. Exp Ther Med 2020;19(4):3024-30. https://doi.org/10.3892/etm.2020.8531.

3. Pavlovic V, Ciric M, Jovanovic V, Stojanovic P. Platelet rich plasma: A short overview of certain bioactive components. Open Med (Wars) 2016;11(1):242-7. https://doi.org/10.1515/med-2016-0048.

4. Abu-Ghname A, Perdanasari AT, Reece EM. Principles and applications of fat grafting in plastic surgery. Semin Plast Surg 2019;33(3):147-54. https://doi.org/10.1055/s-0039-1693438.

5. Cavallo C, Roffi A, Grigolo B, Mariani E, Pratelli L, Merli G, et al. Platelet-rich plasma: The choice of activation method affects the release of bioactive molecules. Biomed Res Int 2016;2016:6591717.

https://doi.org/10.1155/2016/6591717.

6. Choi J, Minn KW, Chang H. The efficacy and safety of platelet-rich plasma and adipose-derived stem cells: An update. Arch Plast Surg 2012;39(6):585-92. https://doi.org/10.5999/aps.2012.39.6.585.

7. Gentile P, Garcovich S. Systematic review: Adipose-derived mesenchymal stem cells, platelet-rich plasma and biomaterials as new regenerative strategies in chronic skin wounds and soft tissue defects. Int J Mol Sci 2021;22(4):1-14. https://doi.org/10.3390/ijms22041538.

8. Gentile P, Garcovich S. Autologous activated platelet-rich plasma (AA-PRP) and non-activated (A-PRP) in hair growth: A retrospective, blinded, randomized evaluation in androgenetic alopecia. Expert Opin Biol Ther 2020;20(3):327-37. https://doi.org/10.1080/14712598.2020.1724951.

9. Safdar A, Shaaban H, Tibayan R, Miller R, Boairdo R, Guron G. The clinical efficacy of using autologous platelet rich plasma in hip arthroplasty: A retrospective comparative study. J Nat Sci Biol Med 2015;6(1):49-55. https://doi.org/10.4103/0976-9668.149077.

10. Maisel-Campbell AL, Ismail A, Reynolds KA, Poon E, Serrano L, Grushchak S, et al. A systematic review of the safety and effectiveness of platelet-rich plasma (PRP) for skin aging. Arch Dermatol Res 2020;312(5):301-15.

https://doi.org/10.1007/s00403-019-01999-6.

11. Paterson KL, Nicholls M, Bennell KL, Bates D. Intra-articular injection of photo-activated platelet-rich plasma in patients with knee osteoarthritis: A double-blind, randomized controlled pilot study. BMC Musculoskelet Disord 2016;17(1):1-9. https://doi.org/10.1186/s12891-016-0920-3.

12. Cook CS, Smith PA. Clinical update: Why PRP should be your first choice for injection therapy in treating osteoarthritis of the knee. Curr Rev Musculoskelet Med 2018;11(4):583-92. https://doi.org/10.1007/s12178-018-9524-x.

13. da Silva FA, Rodrigues BL, Huber SC, Júnior JL, Lana JF, Montalvão SA, et al. The use of platelet rich plasma in the treatment of refractory Crohn's disease. Int J Clin Exp Med 2017;10(5):7533-42.

14. Alcaraz J, Oliver A, Sánchez JM. Platelet-rich plasma in a patient with cerebral palsy. Am J Case Rep 2015;16:469-72. https://doi.org/10.12659/ajcr.893805.

15. Hulimavu S, Reddy R, Reddy R, Babu NC, Ashok GN. Stem cell therapy and platelet rich plasma in regenerative medicines: A review on pros and cons of the technologies. J Oral Maxillofac Pathol 2018;22(3):367-74 https://doi.org/10.4103/jomfp.jomfp_93_18.

16. Nagata MJ, Messora MR, Furlaneto FA, Fucini SE, Bosco AF, Garcia VG, et al. Effectiveness of two methods for preparation of autologous platelet-rich plasma: An experimental study in rabbits. Eur J Dent 2010;4(4):395-402. https://doi.org/10.1055/s-0039-1697859.

17. Marx RE. Platelet-rich plasma: Evidence to support its use. J Oral Maxillofac Surg 2004;2(4):489-96

18. Gentile P, Cole JP, Cole MA, Garcovich S, Bielli A, Scioli MG, et al. Evaluation of not-activated and activated PRP in hair loss treatment: Role of growth factor and cytokine concentrations obtained by different collection systems. Int J Mol Sci 2017;18(2):1-16. https://doi.org/10.3390/ijms18020408.

19. Tomaiuolo M, Brass LF, Stalker TJ. Regulation of platelet activation and coagulation and its role in vascular injury and arterial thrombosis. Interv Cardiol Clin 2017;6(1):1-12

https://doi.org/10.1016/j.iccl.2016.08.001

20. Mohiuddin A, Lewis P, Choudhury K, Sadiq B. Clinical outcome of photoactivated platelet-rich plasma in the treatment of knee osteoarthritis. Rheumatol Orthop Med 2019;4(1):1-4.

21. Zhevago NA, Samoilova KA. Pro and anti-inflammatory cytokine content in human peripheral blood after its transcutaneous (in vivo) and direct (in vitro) irradiation with polychromatic visible and infrared light. Photomed Laser Surg 2006;24(2):129-39. https://doi.org/10.1089/pho.2006.24.129.

22. Sigmundsdottir $H$, Johnston A, Gudjonsson JE, Valdimarsson $H$. Narrowband-UVB irradiation decreases the production of pro-inflammatory cytokines by stimulated $T$ cells. Arch Dermatol Res 2005;297(1):39-42 https://doi.org/10.1007/s00403-005-0565-9.

23. Freitag J Ben, Barnard $A$. To evaluate the effect of combining photo-activation therapy with platelet-rich plasma injections for the novel treatment of osteoarthritis. BMJ Case Rep 2013;2013:bcr2012007463. https://doi.org/10.1136/bcr-2012-007463.

24. Freitag J. The effect of photoactivated platelet-rich plasma injections in the novel treatment of shoulder osteoarthritis. Int J Case Rep Images 2014;5(8):546. https://doi.org/10.5348/ijcri-201496-cr-10407.

25. Chung HY, Kim DH, Lee EK, Chung KW, Chung S, Lee B, et al. Redefining chronic inflammation in aging and age-related diseases: Proposal of the senoinflammation concept. Aging Dis 2019;10(2):367-82 https://doi.org/10.14336/ad.2018.0324

26. Latalski M, Walczyk A, Fatyga M, Rutz E, Szponder T, Bielecki T, et al. Allergic reaction to platelet-rich plasma (PRP): Case report. Medicine (Baltimore) 2019;98(10):e14702. https://doi.org/10.1097/md.0000000000014702.

27. Yun SH, Sim EH, Goh RY, Park JI, Han JY. Platelet activation: The mechanisms and potential biomarkers. Biomed Res Int 2016;2016:10-4. https://doi.org/10.1155/2016/9060143

28. Hu Z, Qu S, Zhang J, Cao X, Wang P, Huang S, et al. Efficacy and safety of platelet-rich plasma for patients with diabetic ulcers: A systematic review and meta-analysis. Adv Wound Care 2019;8(7):298-308. https://doi.org/10.1089/wound.2018.0842.

29. Karina KA, Sobariah S, Rosliana I, Rosadi I, Widyastuti T, Afini I, et al. Evaluation of platelet-rich plasma from diabetic donors shows increased platelet vascular endothelial growth factor release. Stem Cell Investig 2019;6:43. 
https://doi.org/10.21037/sci.2019.10.02.

30. Zhang Y, Ying G, Ren C, Jizhang Y, Borlongan CV, Zhang J, et al. Administration of human platelet-rich plasma reduces infarction volume and improves motor function in adult rats with focal ischemic stroke. Brain Res 2014;1594:267-73.

https://doi.org/10.1016/j.brainres.2014.10.035.

31. Vina M, Camozzi L, Spitaleri MI, Reinchisi G. Hyperconcentrated platelet-rich plasma (High-PRP) for the treatment of a non-healing ulcer of the lateral malleolus: A case report and literature review. CellR4 2020;8:e2873.
32. Karina K, Rosliana I, Rosadi I, Schwartz R, Sobariah S, Afini I, et al. Safety of technique and procedure of stromal vascular fraction therapy: From liposuction to cell administration. Scientifica 2020;2020:2863624. https://doi.org/10.1155/2020/2863624.

33. Moegni KF, Rosliana I, Remelia M, Rosadi I, Sobariah S, Afini I, et al. Stromal vascular fraction (SVF) therapy for treatment of various diseases: Delivering safety of the firs patented SVF technique in Indonesia. Cytotherapy 2019;21(5):S86.

https://doi.org/10.1016/j.jcyt.2019.03.511. 